\title{
Digital Signal Processing: An abstract mathematics to real world experience
}

\author{
Preeti Pillai ${ }^{1}$, Raghavendra $\mathrm{S}^{2}$, Shraddha $\mathrm{B}^{3}$, Nikita $\mathrm{P}^{4}$, Nalini Iyer ${ }^{5}$ \\ Department of Instrumentation Technology, \\ B.V. Bhoomaraddi College of Engineering \& Technology, Hubli, Karnataka, India \\ ${ }^{1}$ preeti_pillai@bvb.edu, ${ }^{2}$ raghu@bvb.edu, ${ }^{3}$ shraddha_h@bvb.edu, ${ }^{4}$ nikhita_patil@bvb.edu, ${ }^{5}$ nalinic@bvb.edu
}

\begin{abstract}
Teaching large classroom is always a very challenging task for educators. This is due to many difficulties imposed on the teaching-learning process. Digital signal processing (DSP) is now pervasive as it is used in everything from digital photo cameras, MP3 players to automobiles. However many students see DSP as abstract mathematics. This is because of the gap between understanding the mathematical formalism of each concept and being able to make sense of them in practice. Getting students actively participate in learning process and motivating them to fill these gaps is a difficult task [3]. To address this difficulty a "recipe" is suggested i.e. "visualizing" the DSP theory with practical applications like speech processing, image processing and so on will help the students in learning better. Sensory stimulation theory of learning says that majority of knowledge held by adults is through seeing $(75 \%)$ while hearing is the next (13\%) and if multi-senses are stimulated; greater learning because of synergy takes place. This theory encouraged us to develop undergraduate level course activity with the applications of audio processing. In this way students are able to see the results of audio processing in MATLAB plots and analyze the results by varying few design parameters. Thus DSP related theoretical concepts will be studied not just as mathematical abstracts but as a useful tools having sense in real world.
\end{abstract}

Keywords- Signal Processing, Filters, Order, ABET, Program outcomes, SEE

\footnotetext{
Preeti Pillai $^{1}$

Department of Instrumentation Technology,

B.V. Bhoomaraddi College of Engineering \& Technology, Hubli, Karnataka, India

${ }^{1}$ preeti_pillai@bvb.edu
}

\section{INTRODUCTION}

Signal is a source of information in an analog or digital form. Digital Signal Processing techniques improve signal quality by extracting important information and removing unwanted information from the signal. The applications of DSP are widely spread in almost all communication and information sectors such as audio signal processing, video signal processing, image processing and communication devices.DSP finds its applications in many leading technologies such as mobile phones, personal computers, video recorders $\mathrm{CD}$ players and so on.

Digital signal processing course focuses on mathematical representation of real world signals which may be communication signals or biomedical signals and its processing systems. These representations are supported by general definitions, theorems, proofs, rules, theories and transformations. This course is always been catered as mathematical subject without visualizing the importance of the concepts and there usage in real world applications [1]. The students consider this course to be a difficult course. There are many difficulties involved in teaching learning process when it comes to large class room. These difficulties involve in encouraging the student to attend the course delivery by keeping their interest in the subject and making the students to participate actively in the learning process by motivating them. Information and knowledge is grasped easier if more senses of students are activated during the learning process.

The main course modules and pedagogical approach used in delivering the course is explained below

a) Background knowledge testing. This module is presented in the form of Self-assessment test;

b) Basics of discrete time signals and linear time invariant (LTI) discrete systems;

c) Z-transform of discrete signals and discrete system function;

d) Pole / zero diagrams in analysis and synthesis of discrete systems;

f) Discrete Fourier Transform (DFT) and its applications. This module guides how to correlate DFT samples with theirs frequency, explains why DFT spectrum is symmetric, proves the periodic nature of DFT and discusses the concept of frequency resolution.

g) Basics of digital filters. Definition of digital filter, filter specifications. Finite impulse response (FIR) and infinite 
impulse response (IIR) filters are compared. Windowing method is used to design FIR filter. Pole -zero placement and bilinear transformation methods to design IIR filters are explained.

This activity was mainly designed to bridge the gap between understanding the mathematical formalism of each concept and being able to make sense of them in practice.

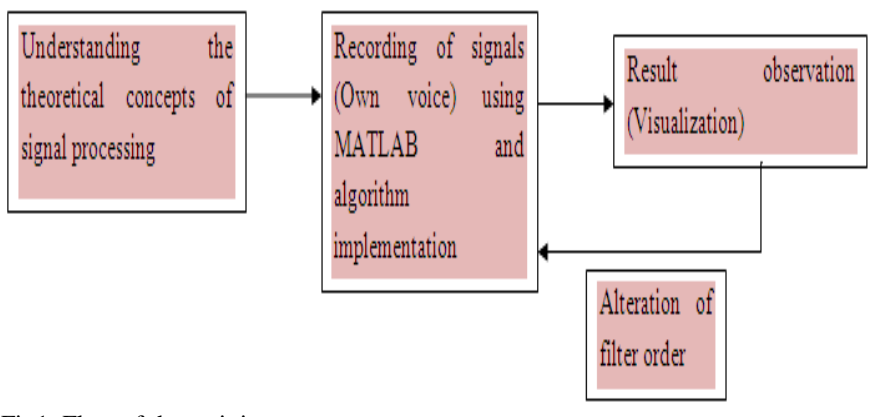

Fig1. Flow of the activity

The figure 1 represents the flow of complete activity focusing on analysis of the signals and its processing by changing design parameters. The basic requirement of the activity was to understand the theoretical concepts of signal processing which is later implemented and visualized using simulation software.

Organization of the paper is as follows, Section 2 deals with the Methodology, Section 3 discusses about implementation details of course project and assessment, Section 4 deals with experimental outcomes and discussion, Section 5 deals with effectiveness of the activity, and Section 6 deals with conclusion.

\section{Methodology}

The details of the course project are presented in this section. Since the subject involves complex mathematical concepts which are difficult for the students to implement in real time. This has been a greatest challenge for the facilitators. This activity has been proposed to go beyond teaching by inculcating analysis concept using mathematical tools, by providing hands on experience to the students on the theoretical concepts and correlating them to solve real world problems.

The students have to use the mind maps [11] concept being taught in lower semester as a basic foundation to initiate this activity.

At the end of the first phase student is expected to understand the theoretical concepts to be implemented and be aware of simulation software (MATLAB). The second phase focuses on recording of real world signal (own voice) with analysis of different recording parameters like Nyquist criteria, sampling frequency, time period etc. The recorded voice is passed through designed filter for further analysis.

The complete activity explained above has been divided into the stages such as,

- Group formation: In this the students in a group of four have to record speech signal and distribute different operations among the group. They should be able to analyze a real world problem by correlating different concepts dealt in course.

- Recap Session: In this session students have to quickly recall the concepts through mind map [11] of signals and systems course and analyze the concepts.

- Simulation stage: In this stage the students in the group perform various operations on recorded speech using programming tool MATLAB.

- Analysis stage: In this stage the students has to perform analysis on the recorded speech signal for varying design parameters of the filter and its order.

- Extended Learning: Focuses on core academic learning with detailed qualitative analysis which in turn leads to scope for improvement beyond curriculum.

- Report Writing: Information collected is organized for meaningful interpretation and analysis and submitted in the form of report, reflecting all the activity details.

\section{IMPLEMENTATION}

This section deals with the details of activity execution and assessment methodologies

As a facilitator, faculty has to foster the students reasoning from front end explanation through theoretical lectures to the back end through recording of speech and analysis.

3.1 Activity execution involves various stages as mentioned below

- Concept analysis through mind mapping and theoretical lectures.

- Gaining of practical experience through performing simulation of theoretical concepts on recorded speech signal and analyzing by playing the processed signal.

- Analyze the signal with changing parameter of system design and playing back.

- Demonstrate effectively the built signal processing system. In addition to this, every team has to prepare videos demonstrating the working model of the system.

Discussion of Case study,

The signal processing technique widely used in real world is filtering. The raw recorded data (signal) is highly contaminated with noise, generated with various source like speaker noise, electrical noise, channel noise, etc. The noise has to be eliminated with proper signal processing algorithms (Filters) as mentioned below,

$y[n]=\frac{1}{a_{0}}\left(\sum_{i=0}^{P} b_{i} x[n-i]-\sum_{j=1}^{Q} a_{j} y[n-j]\right)$

Where $x(n)$ are the real world input samples and bi, aj are the filter system coefficients

Low-pass with cut-off frequency $\Omega$ c to high-pass cut-off frequency $\Omega c^{*}$ : 
$s \rightarrow\left(\frac{\Omega_{c} \Omega_{c}^{*}}{s}\right)$

The system function of the high pass filter is then,

$$
\begin{aligned}
& H(s)=H_{p}\left(\frac{\Omega_{c} \Omega_{c}^{*}}{s}\right) \\
& |H(j \Omega)|=\frac{A}{\left[1+\left(\frac{\Omega}{\Omega_{c}}\right)^{2 N}\right]^{0.5}} \\
& N=\frac{1}{2} \frac{\log \left\{\left[\frac{\left.\left(\frac{1}{\partial_{2}^{2}}-1\right)\right]}{\left.\left.\left(\frac{1}{\partial_{1}^{2}}-1\right)\right]\right\}}\right.\right.}{\log \left(\frac{\Omega_{2}}{\Omega_{1}}\right)} \\
& \Omega_{c}=\frac{\Omega_{1}}{\left[\left(\frac{1}{\delta_{1}}\right)^{2}\right]^{\frac{1}{2 N}}}
\end{aligned}
$$

The values of $\Omega 1$ and $\Omega 2$ are obtained from BTT $\Omega=(2 / \mathrm{T}) \tan (\omega / 2)$, or IIT $\Omega=(\omega / \mathrm{T})$

$$
H(s)=\prod_{k=1}^{\frac{N}{2}} \frac{B_{k} \Omega_{c}^{2}}{s^{2}+b_{k} \Omega_{c} s+c_{k} \Omega_{c}^{2}}, N=2,4,6 .
$$$$
H(s)=\frac{B_{0} \Omega_{c}}{s+c_{0} \Omega_{c}^{2}} \prod_{k=1}^{\frac{N-1}{2}} \frac{B_{k} \Omega_{c}^{2}}{s^{2}+b_{k} \Omega_{c} s+c_{k} \Omega_{c}^{2}}, N=3,5,7
$$

For High pass transformation,

$$
s \rightarrow\left(\frac{\Omega_{c} \Omega_{c}^{*}}{s}\right)
$$

The response of the filters with different order has been shown in the Fig2.

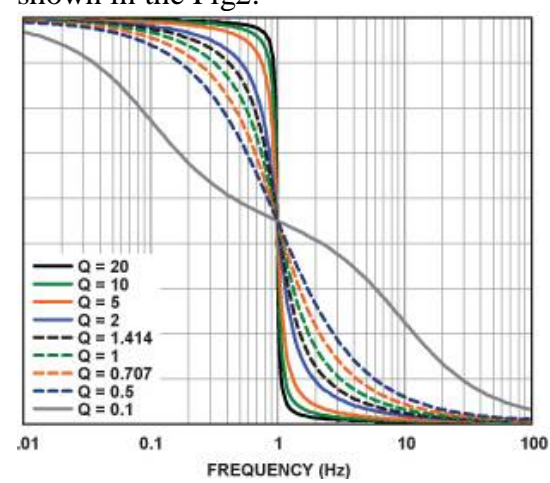

Fig2: Filter response with changing order.
Signal processing on original recorded signal: Fig3 shows the sample algorithm implemented by students to perform processing and analyze the results.

recObj = audiorecorder;

disp('Start speaking.')

recordblocking(recObj, 15);

disp('End of Recording.');

play(recObj);

$\mathrm{AA}=$ getaudiodata $(\mathrm{recObj})$;

plot(AA);

$[\mathrm{a}, \mathrm{b}]=$ butter $(3,0.6)$;

$\mathrm{x}=$ filter $(3,0.6)$

$\operatorname{Plot}(\operatorname{abs}(\mathrm{fft}(\mathrm{x})))$

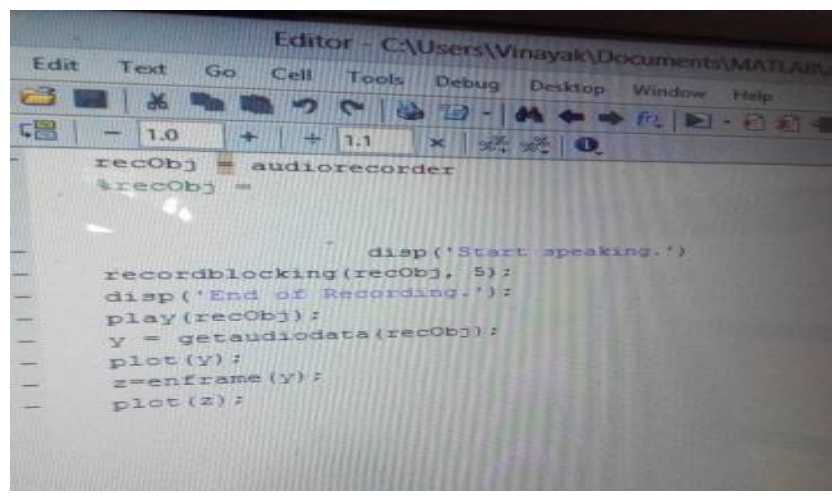

Fig3: Algorithm implementation in MATLAB

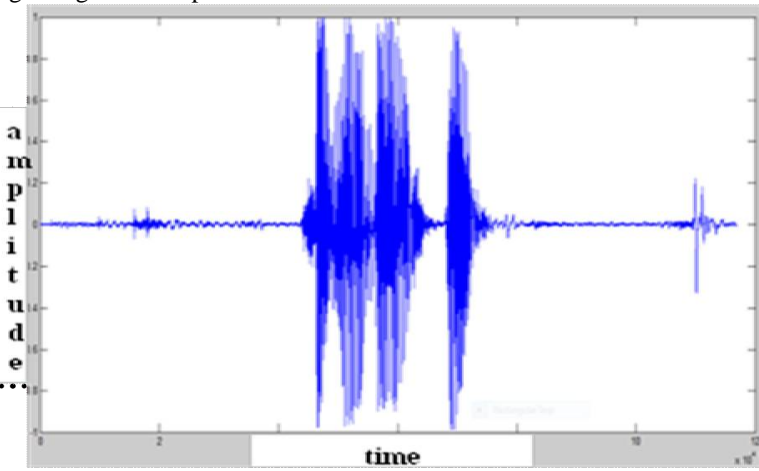

Fig4: Recorded original signal in time domain

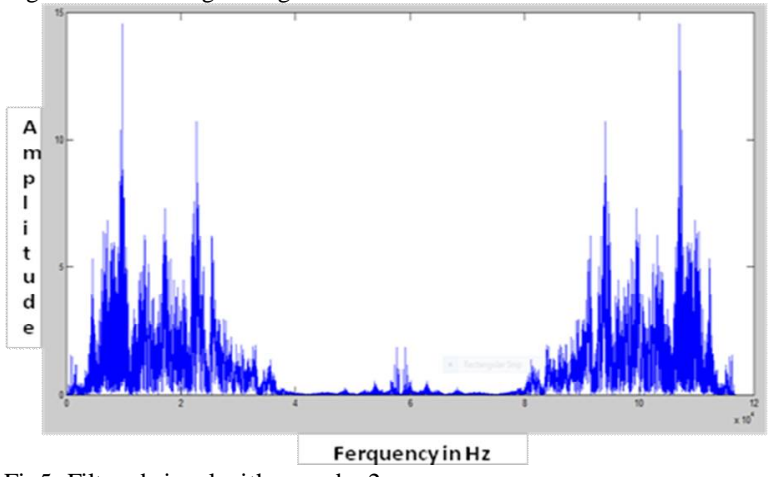

Fig5: Filtered signal with an order 2 


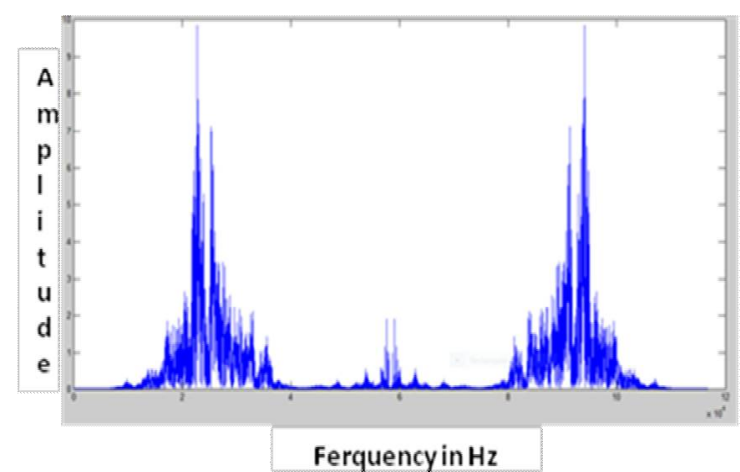

Fig6: Filtered signal with an order 6

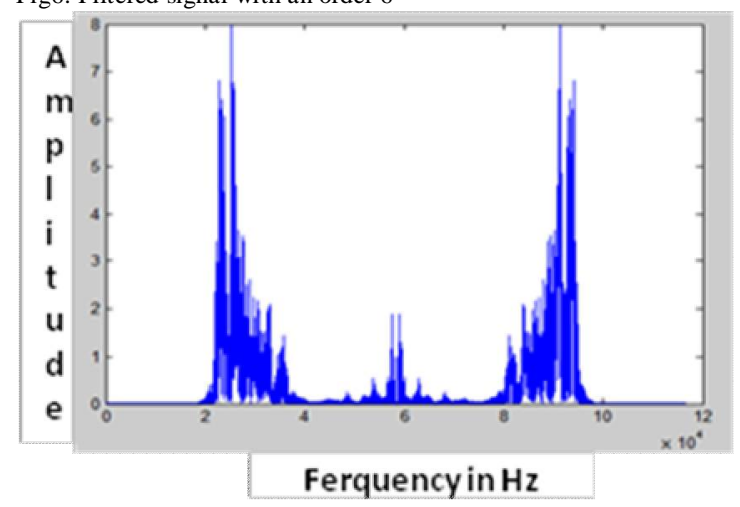

Fig7: Filtered signal with an order 20

The figure4 shows the original recorded signal in time domain. The activity helped the students to realize that the information in time domain is limitted, hence they performed transformation and analyzed the signal. Figure5, Figure6 and Figure 7 shows the analysis of signal with changing real time filter parameter (order "N") affecting the system performance, which a student can analyze and experience in real time.

3.2 Assessment: The assessing methods of the activity included students individual contribution and in the group. The assessment criteria for evaluating the performance of the students are as shown in Table. 1

Table 1 Assessment rubrics

\begin{tabular}{|l|l|l|}
\hline S.No. & Assessment criteria & Weightage \\
\hline 1 & $\begin{array}{l}\text { Therotical component chosen for } \\
\text { problem solving. }\end{array}$ & $20 \%$ \\
\hline 2 & $\begin{array}{l}\text { Real world signal capturing with } \\
\text { appropriate system parameters }\end{array}$ & $20 \%$ \\
\hline 3 & $\begin{array}{l}\text { Design of appropriate signal } \\
\text { processing algorithm }\end{array}$ & $15 \%$ \\
\hline 4 & $\begin{array}{l}\text { Ability to use simulation } \\
\text { software }\end{array}$ & $20 \%$ \\
\hline 5 & $\begin{array}{l}\text { Analysis of processed real world } \\
\text { signal }\end{array}$ & $25 \%$ \\
\hline
\end{tabular}

\section{EXPERIMENTAL OUTCOMES AND DISCUSSION}

The results and outcomes of the course project is mapped to the learning outcomes a to $\mathrm{k}$ of Accreditation Board for Engineering and Technology (ABET) [6] criteria as shown in Table 2.
Table 2 Activity outcomes mapping to ABET program outcomes

\begin{tabular}{|c|c|c|c|}
\hline Step & $\begin{array}{l}\text { Outcome } \\
\text { expected }\end{array}$ & $\begin{array}{l}\text { Performance } \\
\text { Indicators } \\
\text { attaining the } \\
\text { Program } \\
\text { outcomes }\end{array}$ & $\begin{array}{l}\text { Program } \\
\text { outcomes } \\
\text { a-k } \\
\text { criteria's } \\
\text { addressed }\end{array}$ \\
\hline Surveying & $\begin{array}{l}\text { - Identify the } \\
\text { resources to } \\
\text { meet the } \\
\text { desired needs. } \\
\text { - To enhance } \\
\text { exploring } \\
\text { nature of } \\
\text { learners, } \\
\text { making of } \\
\text { literature } \\
\text { survey, } \\
\text { access } \\
\text { technical } \\
\text { papers } \\
\text { - Ability to } \\
\text { identify the } \\
\text { requirements } \\
\text { of the } \\
\text { industry/socie } \\
\text { ty of a given } \\
\text { an to to } \\
\text { engineering } \\
\text { problem. } \\
\text { - Ability to to } \\
\text { define roles } \\
\text { and } \\
\text { responsibilitie } \\
\text { s of team } \\
\text { members. } \\
\text { - Ability to } \\
\text { contribute } \\
\text { effectively to } \\
\text { the team } \\
\text { discussions. } \\
\text { - Awareness } \\
\text { about the } \\
\text { importance of } \\
\text { learning } \\
\text { beyond } \\
\text { curriculum } \\
\text { using } \\
\text { technical } \\
\text { library } \\
\text { interacting } \\
\text { and expents. } \\
\text { participating } \\
\text { in technical } \\
\text { events }\end{array}$ & $\operatorname{ITOE}(\mathrm{c})-1 \mathrm{~B}$ & $\mathrm{c}, \mathrm{d}, \mathrm{i}$ \\
\hline Team work & $\begin{array}{l}\text { To enhance } \\
\text { leadership } \\
\text { qualities }\end{array}$ & ITOE(d)-1B & d \\
\hline
\end{tabular}




\begin{tabular}{|l|l|l|l|}
\hline $\begin{array}{l}\text { Simulate } \\
\text { algorithm }\end{array}$ & $\begin{array}{l}\text { Ability to use } \\
\text { EDA tools for } \\
\text { modeling and } \\
\text { simulation. }\end{array}$ & ITOE(k)-1A & k \\
\hline Presentation & $\begin{array}{l}\text { To improve oral } \\
\text { communication } \\
\text { skills }\end{array}$ & ITOE(g)-2B & $\mathrm{g}$ \\
\hline $\begin{array}{l}\text { Report } \\
\text { writing }\end{array}$ & $\begin{array}{l}\text { To improve } \\
\text { written ITOE(g)-1A } \\
\text { communication } \\
\text { skills }\end{array}$ & $\mathrm{g}$ \\
\hline
\end{tabular}

Activity as a learning technique is mapped to the learning outcomes a to $\mathrm{k}$ of Accreditation Board for Engineering and Technology (ABET)[6] criteria. The attainment of Program outcomes through performance indicators is shown in the Figure 8

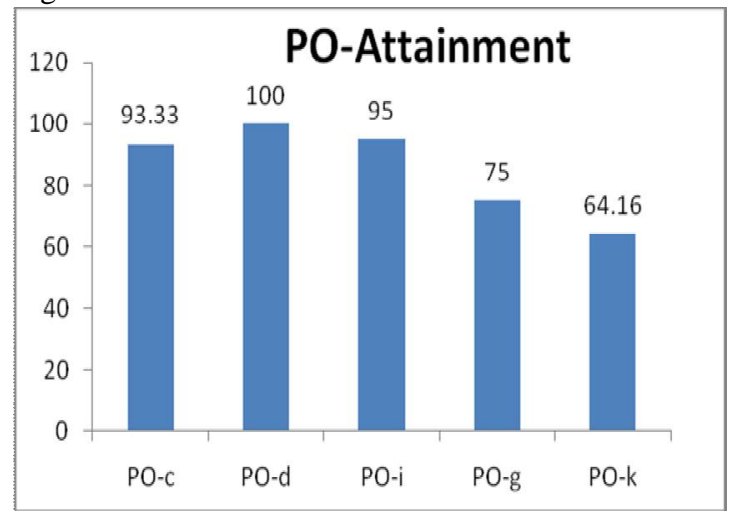

Fig8:Program Outcomes Attainment through Performance Indicators

By the above graph we can infer that by adopting this learning centric method we are able to achieve the outcomes c, d, i, g, k. A number of improvement points have been identified through this measurement[10]. The students ability to solve a real world problem through therotical concepts has been addrtessed and fostered.

\section{EFFECTIVENESS OF THE ACTIVITY}

The effectiveness of the activity has been assessed through the student's performance before and after conduction of the activity. Comparison of the semester end results of the academic year 2013-14 to the academic year 2014-15 for DSP course is been done and feedback is collected by the students. With this activity, students were able to have hands on experience to analyze real world signals with the concepts learnt in the class.

Feedback Questionnaires for this activity is listed in Table. 3

Table 3: Questionnaires For Student Feedback

\begin{tabular}{|l|l|}
\hline Q.No. & Particulars \\
\hline 1. & $\begin{array}{l}\text { In future where will this activity help you in } \\
\text { better understanding in other courses and } \\
\text { project? }\end{array}$ \\
\hline
\end{tabular}

\begin{tabular}{|l|l|}
\hline 2. & $\begin{array}{l}\text { Did this activity enhance the purpose and } \\
\text { justification towards learning the concepts in } \\
\text { different courses? }\end{array}$ \\
\hline 3. & $\begin{array}{l}\text { After this activity how do you rate the } \\
\text { understanding level of the course? }\end{array}$ \\
\hline 4. & $\begin{array}{l}\text { Did technique inspire you for collaborative } \\
\text { learning? }\end{array}$ \\
\hline 5. & Any other comments or feedback. \\
\hline
\end{tabular}

Question 1 relates to whether the students will use this learning technique in future for interactive learning in other courses and project. In response students suggested that this activity helps them in providing better analysis of different concepts and make them capable of problem solving. Question 2 reflects on why the students are learning the particular concepts, where it is used and how the concept is applied, and in response $90 \%$ students agreed that this learning method helped them to apply the concepts studied in solving real time problems. For question $3 \& 4$, an achievement of $85 \%$ is observed to justify better understanding of the concept and $90 \%$ in enhancement in collaborative learning as shown in Figure 8

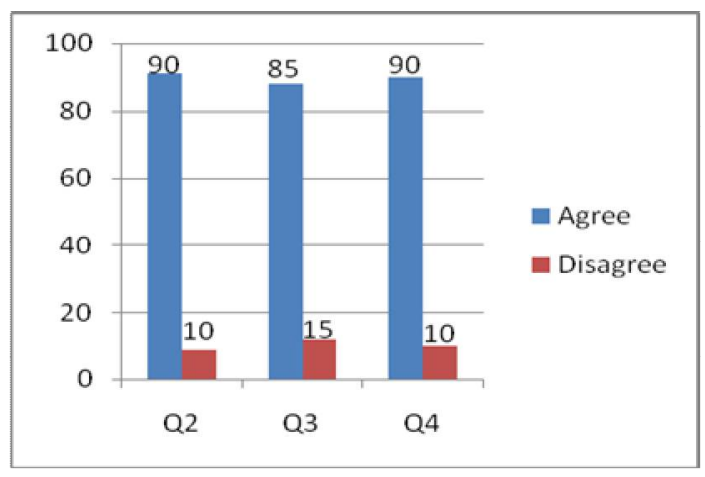

Fig9: Feedback Summary of activity by students

The effectiveness of the progressive activity has been reflected in the performance of students. The performance of students in the academic year 2013-14 for DSP is compared with the performance of the students in the academic year 2014-15 and is observed that the percentage of the class result is increased as shown in Figure 9.

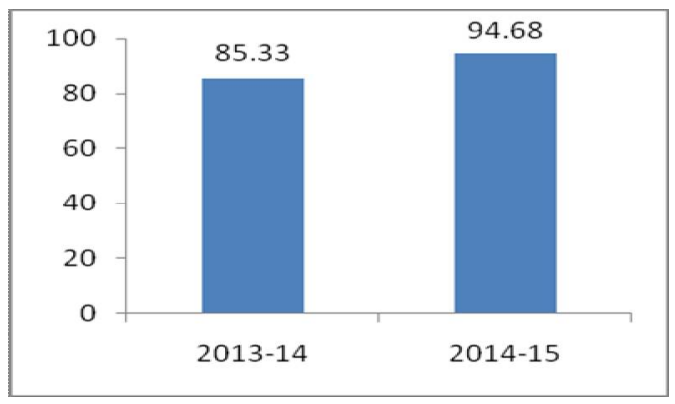

Fig10: Comparison of Semester end results 


\section{CONCLUSION}

This paper reflects the student's exposure to the practical learning experience, students learn and interpret the concepts to solve real time problems. As this is a mathemitical oriented subject, students were motivated to learn the course through real world eperience and its analysis. The most prominent positive outcome of the experiment is that over $90 \%$ of the students have clearly indicated that this has given them a very good opportunity to evaluate, work on and improve their conceptual learning method.

This interactive learning approach adopted has great impact in significantly improving the overall teaching learning process, encouraging the faculty and the students to extend the same to the relevant courses in the curricula program. By this activity we were able to attain the ABET[5] criteria c,d,i, g, k whereas before this subject was only able to attain a.

The overall outcome as seen from the result analysis clearly indicates that the approach adopted has indeed significantly been encouraging in terms of the doing practical hands-on and solve real time problems with the knowledge gained from the activity.

\section{REFERENCES}

[1] Thomas, JW, (2000) "A review of research on project based learning".

[2] Thomas, J.W., Mergendoller, J.R., \&Michaelson, A. (1999) "Project Based Learning: A handbook for middle and high school teachers". Novato, CA: The Buck institute for Education

[3] Jones, B.F., Rasmussen, C.M., \& Moffitt, M.C. (1997). "Real Life problem solving: A collaborative approach to interdisciplinary learning”. Washington, DC: American Psychological Association.

[4] Richard M. Felder, Donald R. Woods, James E. Stice, Armando Rugarcia , 'The Future Of Engineering Education; Teaching Methods That Work' Chem. Engr. Education, 34(1), 26-39 (2000).

[5] V. Marozas, V. Dumbrava, "Motivating the Students to Study the Basics of Digital Signal Processingby using Virtual Learning Environment"

[6] http://www.abet.org/special-reports/

[7] The University of Wisconsin-Madison http://teachingacademy. wisc.edu/archive/Assistance/course/blooms.ht $\mathrm{m}$

[8] Proakis and Manolakis, "Digital Signal Processing” (PHI)/Pearson,3rd edition

[9] http://cft.vanderbilt.edu/teaching-guides/pedagogical/bloomstaxonomy/

[10] http://ww2.odu.edu/educ/roverbau/Bloom/blooms_taxonomy.htm

[11] B Shraddha,Raghavendra Shet, Nikita P'Mind Mapping: An Useful Technique for Effective Learning in Large Classroom"

[12] B Shraddha "Tutorial: A Case Study on Integrated Learning".

[13] Preeti Pillai "Prototype Implementation: An Effective Learning Method in Process Automation". 